\title{
Distinct clinical characteristics and helminth co-infections in adult tuberculosis patients from urban compared to rural Tanzania
}

George Sikalengo ${ }^{1 \dagger}$, Jerry Hella ${ }^{1,2,3^{*}}{ }^{4}$, Francis Mhimbira ${ }^{1,2,3}$, Liliana K. Rutaihwa ${ }^{1,2,3}$, Farida Bani ${ }^{1}$, Robert Ndege ${ }^{1}$, Mohamed Sasamalo ${ }^{1,2,3}$, Lujeko Kamwela ${ }^{1}$, Khadija Said ${ }^{1,2,3}$, Grace Mhalu²,2,3, Yeromin Mlacha ${ }^{1,2,3}$, Christoph Hatz ${ }^{2,3}$, Stefanie Knopp 2,3, Sébastien Gagneux²,3, Klaus Reither ${ }^{2,3}$, Jürg Utzinger ${ }^{2,3}$, Marcel Tanner ${ }^{2,3}$, Emilio Letang 1,2,3, Maja Weisser ${ }^{1,2,3 \dagger}$ and Lukas Fenner ${ }^{1,2,3,4^{*} \dagger}$

\begin{abstract}
Background: Differences in rural and urban settings could account for distinct characteristics in the epidemiology of tuberculosis (TB). We comparatively studied epidemiological features of TB and helminth co-infections in adult patients from rural and urban settings of Tanzania.

Methods: Adult patients ( $\geq 18$ years) with microbiologically confirmed pulmonary TB were consecutively enrolled into two cohorts in Dar es Salaam, with $\sim 4.4$ million inhabitants (urban), and Ifakara in the sparsely populated Kilombero District with $\sim 400000$ inhabitants (rural). Clinical data were obtained at recruitment. Stool and urine samples were subjected to diagnose helminthiases using Kato-Katz, Baermann, urine filtration, and circulating cathodic antigen tests. Differences between groups were assessed by $X^{2}$, Fisher's exact, and Wilcoxon rank sum tests. Logistic regression models were used to determine associations.
\end{abstract}

Results: Between August 2015 and February 2017, 668 patients were enrolled, 460 (68.9\%) at the urban and 208 (31.1\%) at the rural site. Median patient age was 35 years (interquartile range [IQR]: 27-41.5 years), and 454 (68\%) were males. Patients from the rural setting were older (median age 37 years vs. 34 years, $P=0.003$ ), had a lower median body mass index $\left(17.5 \mathrm{~kg} / \mathrm{m}^{2}\right.$ vs. $\left.18.5 \mathrm{~kg} / \mathrm{m}^{2}, P<0.001\right)$, a higher proportion of recurrent TB cases $(9 \%$ vs. $1 \%, P<0.001$ ), and in HIV/TB co-infected patients a lower median CD4 cell counts ( 147 cells $/ \mu$ l vs. 249 cells $/ \mu$ l, $P=$ 0.02) compared to those from urban Tanzania. There was no significant difference in frequencies of HIV infection, diabetes mellitus, and haemoglobin concentration levels between the two settings. The overall prevalence of helminth co-infections was 22.9\% (95\% confidence interval [C]: 20.4-27.0\%). The significantly higher prevalence of helminth infections at the urban site $(25.7 \%$ vs. $17.3 \%, P=0.018)$ was predominantly driven by Strongyloides stercoralis (17.0\% vs. 4.8\%, $P<0.001)$ and Schistosoma mansoni infection (4.1\% vs. $16.4 \%, P<0.001)$. Recurrent TB was associated with living in a rural setting (adjusted odds ratio [aOR]: 3.97, 95\% Cl: 1.16-13.67) and increasing age (aOR: 1.06, 95\% Cl: 1.02-1.10).

Conclusions: Clinical characteristics and helminth co-infections pattern differ in TB patients in urban and rural Tanzania. The differences underline the need for setting-specific, tailored public health interventions to improve clinical management of TB and comorbidities.

Keywords: Co-infection, Helminth infection, Recurrent tuberculosis, Schistosomiasis, Tanzania, Tuberculosis

\footnotetext{
*Correspondence: jhella@ihi.or.tz; lukas.fenner@ispm.unibe.ch

${ }^{\dagger}$ Equal contributors

${ }^{1}$ Ifakara Health Institute, Dar es Salaam, Tanzania

Full list of author information is available at the end of the article
} 


\section{Multilingual abstracts}

Please see Additional file 1 for translations of the abstract into the five official working languages of the United Nations.

\section{Background}

Worldwide, tuberculosis (TB) is the leading cause of mortality from an infectious disease surpassing human immunodeficiency virus (HIV) infection [1]. Globally, the burden of TB is decreasing, but mortality due to TB remains high with 1.4 million $\mathrm{TB}$ deaths and an estimated 10.4 million new cases in 2015 [1]. The global TB case detection rate is below $63 \%$ and even lower in Tanzania with a detection rate ranging from $42 \%$ to $54 \%$ $[2,3]$. This is partly due to frequent delays in TB diagnosis in low-income settings [4-8] ranging from 25 to 185 days [5-7]. Delay in TB diagnosis is associated with increased transmission in the community [9]. A deeper understanding of the epidemiology of TB is needed in order to reach the ambitious vision of the End TB strategy of zero TB discrimination, disease suffering, and deaths by $2035[10,11]$.

In Tanzania the prevalence of TB varies considerably across regions, and is higher among males, older persons, and those with lower socioeconomic status [2]. Studies have shown different epidemiological features of $\mathrm{TB}$ in urban and rural settings due to differences in health-seeking behaviour, knowledge of TB transmission, gender roles, socioeconomic status, and disease burden [12-14]. Rural-urban characteristics and living conditions could account for differences in the epidemiology of TB in Tanzania and elsewhere. Comorbidities such as HIV and helminth co-infections contribute to different treatment outcomes among TB patients [15-17]. We studied differences in the epidemiology of TB and comorbidities such as helminth co-infections and severe anaemia from two population-based TB cohort platforms established since 2013 in Tanzania [18].

\section{Methods}

\section{Study setting}

We included adult patients ( $\geq 18$ years) from an ongoing prospective cohort of bacteriologically confirmed pulmonary TB patients in Tanzania (TB-DAR). TB-DAR was initiated in 2013 as a platform to study clinical and molecular epidemiology of TB in Tanzania. The study has two recruitment sites (Fig. 1): one urban site in the densely populated Temeke district in Tanzania's economic capital, Dar es Salaam, with $\sim 4.4$ million inhabitants, and one in the rural site found within the Ifakara ward in the sparsely populated Kilombero district with $\sim 400000$ inhabitants [19].

\section{Study sites}

Urban site (Dar es Salaam)

The urban site is located in the Temeke District in Dar es Salaam inhabited by about 1.4 million inhabitants (Fig. 1). Patient recruitment was done at the TB clinic of Temeke District Hospital, which is one of three regional referral hospitals in the city. The hospital is the largest healthcare facility in the district that provides specialized care and treatment for the Temeke population. Recruitment of patients started in November 2013 and is ongoing in the second part of 2017 [18, 20-22].

\section{Rural site (Ifakara)}

The rural site is located in the Kilombero District with a population of about 407000 people [19]. Recruitment was done at the Chronic Disease Clinic of Ifakara (CDCI), a clinic for patients infected with HIV and/or TB at the Saint Francis Referral Hospital (Fig. 1). The hospital is the largest healthcare facility of the Kilombero District in the Morogoro Region, located in southern Tanzania, and provides care for residents of Kilombero and the nearby Ulanga District [23]. Patient recruitment started in August 2015 and is ongoing at the time of manuscript writing.

\section{Study population}

We analysed data collected from patients who were consecutively enrolled between August 1, 2015 and February 28, 2017. Patients were eligible for enrollment if they had an age of 18 years or above, lived within the study area, and gave written informed consent. Patients who were severely ill were excluded. Of the 672 bacteriologically confirmed TB patients enrolled in the TB-DAR study during this time period, we excluded four patients due to missing complete clinical information (Fig. 2).

\section{Study procedures}

At recruitment, patients with confirmed pulmonary TB were interviewed and underwent physical examination as previously described $[18,22]$. After recruitment, patients were seen by the study doctor at 6 and 12 months after initiating TB treatment. Of note, TB treatment was supervised by home-based or facility-based direct observation (patient-centered approach) according to the National guideline [24]. Clinical data and biological specimens (sputum, serum, plasma, stool, and urine samples) were collected from all TB patients for laboratory analysis.

\section{Laboratory procedures Microbiological investigations}

Bacteriological confirmation of TB was done by examining the presence of acid fast bacilli (AFB) under fluorescence LED microscope or by using Xpert MTB/RIF 


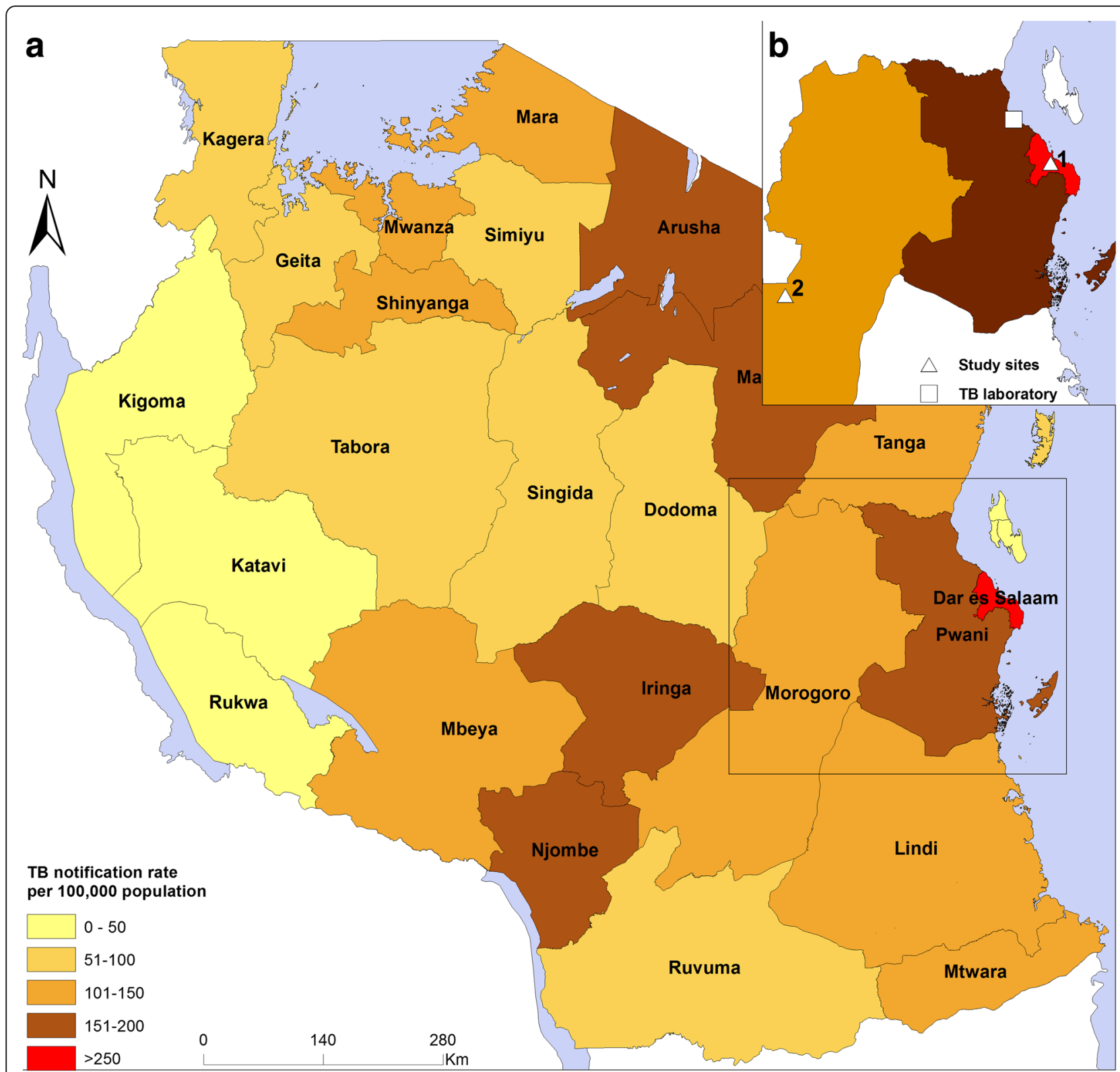

Fig. 1 Map of Tanzania showing the regional tuberculosis (TB) notification rates, the locations of the study sites (triangles), and the TB laboratory (square). a Overview. b Study site 1 (urban), Temeke District, Dar es Salaam Region (triangle); study site 2 (rural), Ifakara, Kilombero District (triangle); and the tuberculosis laboratory in Bagamoyo, Pwani Region

assay (Cepheid; Sunnyvale, USA) in all sputum samples. AFB smear-positive results were graded according to published guidelines [24, 25]. All sputum samples were sent to a biosafety level 2+ TB laboratory for solid culture on Lowenstein-Jensen medium at the Bagamoyo Research and Training Center (BRTC), Bagamoyo, Tanzania (Fig. 1). Sputum samples from Ifakara were preserved in cetylpyridinium chloride (CPC) and sent by post to BRTC in Bagamoyo and processed as previously described [26].

\section{Helminth investigations}

For the diagnosis of helminth infections, stool and urine samples were collected once from each patient before the start of TB treatment. From the rural site, the samples were sent to the Ifakara Health Institute Helminth Laboratory in Ifakara, Tanzania. From the urban site, the samples were transferred to the Helminth Unit at BRTC in Bagamoyo. At each laboratory, samples were examined for helminth infection using standardized, qualitycontrolled procedures as previously described [18, 27]. 


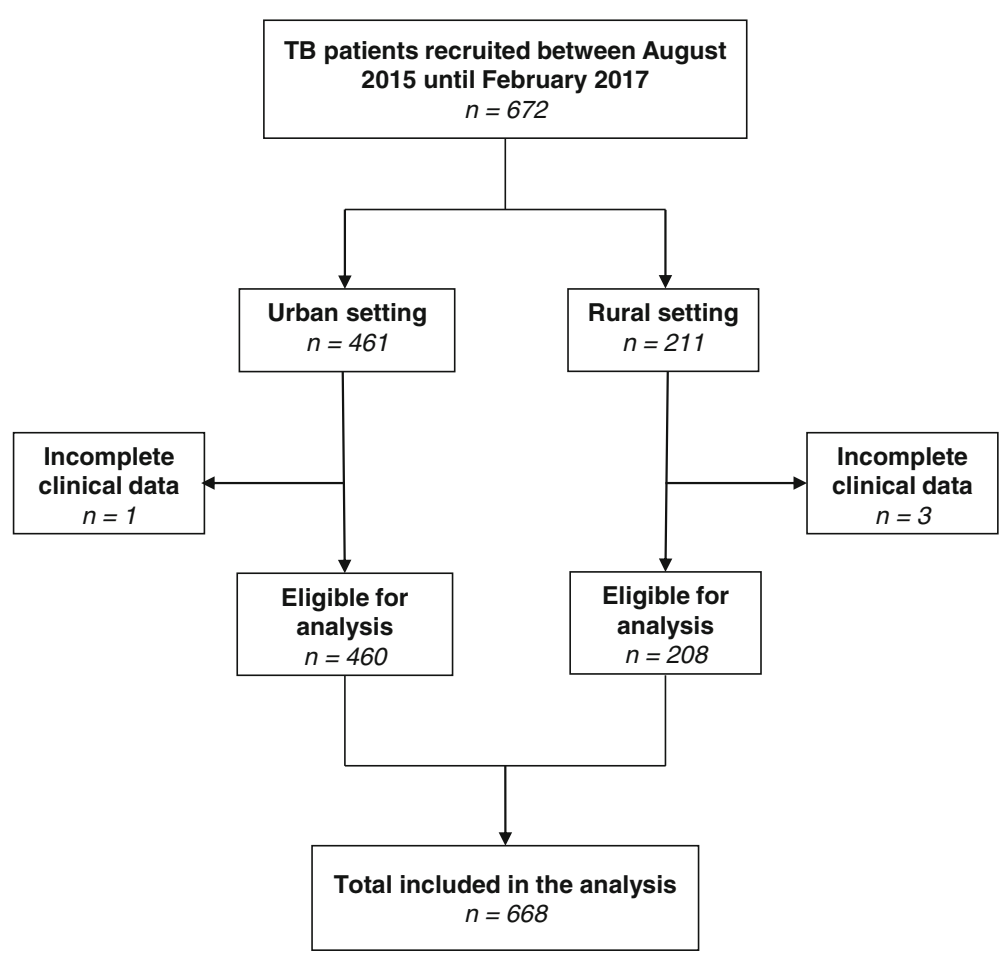

Fig. 2 Selection of study patients

The Kato-Katz method was performed in triplicate with thick stool smears from each sample to diagnose Ascaris lumbricoides, hookworm, Schistosoma mansoni, and Trichuris trichiura infection. Strongyloides stercoralis infection was diagnosed by the Baermann method [27]. Microhaematuria was examined by reagent strips (Hemastix; Siemens Healthcare Diagnostics Inc.; Tarrytown, USA). Additionally, a point-of-care circulating cathodic antigen (POC-CCA) urine cassette test (ICT Diagnostics, Noordhoek, South Africa) was employed for rapid diagnosis of S. mansoni [28]. S. haematobium eggs were detected using urine filtration [18, 29]. For quality control, $10 \%$ of the Kato-Katz slides were randomly selected and re-examined by a senior laboratory technician at each site [27].

\section{Other laboratory investigations}

HIV screening was done using the Alere Determine HIV rapid test (Alere; San Diego, USA) following national HIV testing algorithms; the Uni-gold HIV rapid test (Trinity Biotech; Wicklow, Ireland) served as a confirmatory test in the event of a positive screening test. In HIV-positive patients, CD4 cell counts were determined by flow cytometry (FACS Calibur, Becton Dickinson Biosciences; San Jose, USA) within $3 \mathrm{~h}$ after blood was drawn. A full blood cell count was done with a Sysmex XP-300 (Sysmex Corporation; Kobe, Japan). Blood tests were performed at the Ifakara Health Institute (IHI) laboratories under regular supervision by the quality assurance team.

\section{Data collection and definitions}

At the time of recruitment, clinical officers from the Ifakara Health Institute with extensive experience in clinical research performed physical examinations and interviewed patients using standardized questionnaires $[18,22]$. We collected sociodemographic, clinical, and socioeconomic data from all patients. Data were entered using tablets via the OpenDataKit application (www.opendatakit.org). Data quality was monitored in real-time using the "odk_planner" tool [20].

A TB patient was defined as new detection of Mycobacterium tuberculosis in the sputum by smear microscopy or Xpert MTB/RIF assay [24]. A new TB patient was defined as a person, who had never been treated or whose prior treatment for TB had lasted less than 1 month [28]. Recurrent TB patients (relapse patients) were persons who had been treated previously for TB and had been declared cured or had completed their most recent course of treatment, who then presented with a recurrent episode of TB (either a true relapse or a new episode of TB caused by reinfection) [28].

Severe anaemia was defined as haemoglobin $(\mathrm{Hb})<8.5$ $\mathrm{g} / \mathrm{dl}$. Diabetes mellitus was defined as a random or fasting blood glucose level of $\geq 11.1 \mathrm{mmol} / \mathrm{L}$ or $7 \mathrm{mmol} / \mathrm{L}$ [30]. Patients were considered co-infected with helminths if eggs or 
larvae of the following species in stool or urine microscopy were present: A. lumbricoides, Enterobius vermicularis, Hymenolepis diminuta, hookworm, S. haematobium, S. mansoni, S. stercoralis, and T. trichiura. Additionally, S. mansion infection was defined as a positive POC-CCA urine cassette test. Two forms of helminth infection were distinguished: schistosomiasis, due to infection with either S. mansoni or S. haematobium; and other helminthiases, which included infection with A. lumbricoides, E. vermicularis, $H$. diminuta, hookworm, S. stercoralis, or T. trichiura. Occupational risk for acquiring helminth infection was defined as working in rice fields, car washing, or sand harvesting pits, and fishing in rivers or still bodies of natural freshwater. TB diagnosis delay was recorded whenever more than 3 weeks elapsed between occurrence of patient's first TB symptom(s) and TB diagnosis was made [22].

\section{Statistical and geographical analysis}

Descriptive statistics were employed for characterizing patients. For continuous variables, the Wilcoxon rank-sum or Student's $t$-tests were used, depending on the distribution from the two sites, and $\chi^{2}$ or Fisher's exact tests for comparison of categorical variables, as appropriate. We set the threshold of a statistically significant difference at an alpha level of 0.05 . Univariate and multivariate logistic regression models were fitted to assess the association between recurrent $\mathrm{TB}$ with different epidemiological characteristics among TB patients. Additionally, we analysed the association of helminth co-infections and different predictors in a logistic regression model adjusted for age, sex, HIV infection, individual deworming history, occupational risk, and site (urban/rural). All analyses were performed in Stata version 13.1 (Stata Corporation; College Station, USA).

We collected geo-coordinates using Android tablets from the two study sites and the TB laboratory. The Tanzania regions shapefiles were obtained from the Tanzanian National Bureau of Statistics, and merged with the corresponding annual TB notification rates in 2015 obtained from the National Tuberculosis and Leprosy Programme. We used ArcGIS version 10.4 (Esri; Redlands, USA) to produce the map.

\section{Results}

\section{Comparison of patient characteristics in the urban and rural setting}

We studied 668 patients enrolled between August 2015 and February 2017, $460(68.9 \%)$ at the urban and the remaining $208(31.1 \%)$ at the rural site (Table 1). Their median age was 35 years (interquartile range [IQR]: 2741.5 years), and $454(68.0 \%)$ were males. Rural patients were older than those from the urban setting (median age 37 years, IQR: $27-46$ years, vs. 34 years, IQR: 2740 years; $P=0.003$ ). Prevalence of HIV infection was similar in the two settings $(59 / 208$ [28.4\%] in the rural vs. $108 / 460$ [23.5\%] in the urban setting, $P=0.18$ ). Among HIV-positive patients from the rural setting, start of anti-retroviral treatment (ART) was delayed after HIV diagnosis compared to those from the urban setting (median time to start of ART 24 days [IQR: 11-64 days] vs. 14 days [IQR: $11.5-20.5$ days], $P=0.001$ ). The proportion of a contact history with a TB case was higher in rural compared to urban patients $(20.2 \%, 95 \%$ CI: $14.7-$ $25.6 \%$ vs. $12.8 \%, 95 \% C I$ : $9.8-15.9 \%, P=0.014)$. Body mass index (BMI) at the time of TB diagnosis was significantly lower among rural patients than their urban counterparts (median $17.5 \mathrm{~kg} / \mathrm{m}^{2}$ [IQR: $16.2-19.6 \mathrm{~kg} / \mathrm{m}^{2}$ ] vs. $18.5 \mathrm{~kg} / \mathrm{m}^{2}$ [IQR: $17-20.3 \mathrm{~kg} / \mathrm{m}^{2}$ ], $\left.P<0.001\right)$.

At the time of $\mathrm{TB}$ diagnosis, mean $\mathrm{Hb}$ levels were comparable in both groups. Among HIV-positive TB patients, the median $\mathrm{CD} 4$ cell count was lower in the rural compared to the urban setting (147 cells/ $\mu$ l[QR: $84-$ 246 cells $/ \mu \mathrm{l}]$ vs. $249 \mathrm{CD} 4 \mathrm{cells} / \mu \mathrm{l}$ [IQR $131-450 \mathrm{cells} / \mu \mathrm{l}]$, $P=0.02$ ). Among 630 patients whose blood glucose levels were tested, 17/630 (2.5\%) were diagnosed as diabetic. Prevalence of diabetes in the TB patients did not differ between the two settings.

TB patients in the rural setting were less likely to selfaccess anthelminthic medications than urban patients (73/208 [35.1\%] vs. 304/460 [66.1\%], $P<0.001)$ and had less access to mass deworming campaigns in the last 12 months at the time of recruitment $(10 / 208$ [4.8\%] vs. $73 / 460$ [15.9\%], $P<0.001$ ).

\section{Comparison of recurrent TB cases in the urban and rural setting}

In the rural setting, 18/208 (10.0\%) were recurrent (relapse) TB cases compared to $6 / 460(1.3 \%)$ in the urban setting. Patients with recurrent TB were older than patients with a first TB episode ( 47 years vs. 35 years), 22 of the 24 patients with recurrent TB were males, and 14 were not employed. Rural recurrent TB patients had a higher median body fat percentage than those from the urban setting $(11.9 \%$ vs. $7.1 \%, P=0.005)$. Characteristics of recurrent TB patients are described in Table 2.

In a multivariate logistic regression model, we found that rural patients were more likely to have recurrent TB than urban patients (adjusted odds ratio [aOR]: 3.97, 95\% $C I$ : 1.16-13.67, $P=0.029$ ). Furthermore, for each 1-year increase in age, the adult TB patient risk of developing recurrent TB increased by $6 \%$ (aOR: 1.06, 95\% CI: 1.02-1.10, $P=0.001$ ). We found that patients who were underweight $\left(\mathrm{BMI}<18.5 \mathrm{~kg} / \mathrm{m}^{2}\right)$ had a higher risk of recurrent TB (aOR: 2.97, 95\% CI: 0.85-10.30, $P=0.087$; Table 3).

\section{Comparison of helminth co-infections patterns and associated risk factors in the urban and rural settings}

The overall prevalence of helminth co-infections in TB patients was $23.1 \%$. As shown in Table 4, the prevalence 
Table 1 Sociodemographic and clinical characteristics of adult tuberculosis (TB) patients at the time of diagnosis, enrolled between August 2015 and February 2017 in Dar es Salaam (urban) and Ifakara (rural), Tanzania

\begin{tabular}{|c|c|c|c|c|}
\hline Characteristics & All & Urban & Rural & $P$-value \\
\hline Total & 668 & 460 & 208 & \\
\hline Age groups in years, $n(\%)$ & & & & 0.001 \\
\hline $18-24$ & $112(16.8)$ & $78(17.0)$ & $34(16.4)$ & \\
\hline $25-33$ & $199(29.8)$ & $151(32.8)$ & $48(23.1)$ & \\
\hline $34-43$ & $220(32.9)$ & $155(33.7)$ & $65(31.3)$ & \\
\hline$\geq 44$ & $137(20.5)$ & $76(16.5)$ & $61(29.3)$ & \\
\hline Sex, $n(\%)$ & & & & 0.81 \\
\hline Female & $214(32.0)$ & $146(31.7)$ & $68(32.7)$ & \\
\hline Male & $454(68.0)$ & $314(68.3)$ & $140(67.3)$ & \\
\hline \multicolumn{5}{|l|}{ HIV status, $n(\%)$} \\
\hline Negative & $497(74.4)$ & $352(76.5)$ & $145(69.7)$ & \\
\hline Positive & $167(25.0)$ & $108(23.5)$ & $59(28.4)$ & 0.18 \\
\hline Unknown & $4(0.6)$ & 0 & $4(1.9)$ & \\
\hline Time to ART initiation in days, median (IQR) & $15(11-35)$ & $14(11.5-20.5)$ & $24(11-64)$ & 0.001 \\
\hline Education level, $n$ (\%) & & & & 0.85 \\
\hline No/primary & $552(82.6)$ & $381(82.8)$ & $171(82.2)$ & \\
\hline Secondary/university & $116(17.4)$ & $79(17.2)$ & $37(17.8)$ & \\
\hline Occupation, $n(\%)$ & & & & $<0.001$ \\
\hline Unemployed & $257(38.5)$ & $100(21.7)$ & $157(75.5)$ & \\
\hline Employed & $411(61.5)$ & $360(78.3)$ & $51(24.5)$ & \\
\hline Smoking status ${ }^{a}, n(\%)$ & $166(24.9)$ & $122(26.5)$ & $44(21.2)$ & 0.18 \\
\hline Alcohol abuse $^{b}, n(\%)$ & $158(23.7)$ & $105(22.8)$ & $53(25.5)$ & 0.46 \\
\hline People in the household, $n(\%)$ & & & & $<0.001$ \\
\hline$\leq 3$ & $428(64.1)$ & $315(68.5)$ & $113(54.3)$ & \\
\hline$>3$ & $240(35.9)$ & $145(31.5)$ & $95(45.7)$ & \\
\hline History of TB contact, $n(\%)$ & $101(15.1)$ & $59(12.8)$ & $42(20.2)$ & 0.014 \\
\hline Household monthly income, $n(\%)$ & & & & 0.032 \\
\hline$<100$ USD & $459(68.7)$ & $328(71.3)$ & $131(63.0)$ & \\
\hline$\geq 100$ USD & $209(31.3)$ & $132(28.7)$ & $77(37.0)$ & \\
\hline Patient category & & & & $<0.001$ \\
\hline New case & $643(96.3)$ & $454(98.7)$ & $189(90.9)$ & \\
\hline Recurrent case & $24(3.5)$ & $6(1.3)$ & $18(8.7)$ & \\
\hline Return after lost to follow-up case & $1(0.2)$ & 0 & $1(0.5)$ & \\
\hline $\mathrm{BMI}\left(\mathrm{kg} / \mathrm{m}^{2}\right)$, median $(\mathrm{IQR})$ & $18.3(16.7-20.3)$ & $18.5(17-20.4)$ & $17.5(16.2-19.6)$ & $<0.001$ \\
\hline BMI categories in kg/m², $n(\%)$ & & & & 0.001 \\
\hline Underweight, $<18.5$ & $362(54.2)$ & $229(49.8)$ & $133(63.9)$ & \\
\hline Normal, 18.5-24.9 & $278(41.6)$ & $205(44.6)$ & $73(35.1)$ & \\
\hline Overweight, 25.0-29.9 & $21(3.1)$ & $20(4.4)$ & $1(0.5)$ & \\
\hline Obese, $\geq 30$ & $7(1.1)$ & $6(1.3)$ & $1(0.5)$ & \\
\hline $\mathrm{Hb}$ level in g/dl, median (IQR) & $11.0(9.7-12.5)$ & $11.1(9.9-12.6)$ & $11.0(9.3-12.1)$ & 0.27 \\
\hline Body fat in \%, median (IQR) & $10.8(8.0-14.8)$ & $10.6(7.8-14.8)$ & $11.5(8.3-14.8)$ & 0.087 \\
\hline Diagnosis delay in weeks, median (IQR) & $4(3-8)$ & $4(3-6)$ & $8(4-12)$ & $<0.001$ \\
\hline Diagnosis delay in weeks, $n(\%)$ & & & & $<0.001$ \\
\hline
\end{tabular}


Table 1 Sociodemographic and clinical characteristics of adult tuberculosis (TB) patients at the time of diagnosis, enrolled between August 2015 and February 2017 in Dar es Salaam (urban) and Ifakara (rural), Tanzania (Continued)

\begin{tabular}{|c|c|c|c|c|}
\hline Characteristics & All & Urban & Rural & $P$-value \\
\hline$\leq 3$ weeks & $174(26.1)$ & $153(33.4)$ & $21(10.1)$ & \\
\hline$>3$ weeks & $492(73.9)$ & $305(66.6)$ & $187(89.9)$ & \\
\hline Visiting traditional healers, $n(\%)$ & $86(12.9)$ & $26(5.7)$ & $60(28.9)$ & $<0.001$ \\
\hline \multicolumn{5}{|l|}{ Helminth factors, $n(\%)$} \\
\hline Occupational risk ${ }^{c}$ & $274(41.0)$ & $232(50.4)$ & $42(20.2)$ & $<0.001$ \\
\hline Individual deworming ${ }^{d}$ & $377(56.4)$ & $304(66.1)$ & $73(35.1)$ & $<0.001$ \\
\hline Part of mass drug campaign ${ }^{d}$ & $83(12.4)$ & $73(15.9)$ & $10(4.8)$ & $<0.001$ \\
\hline
\end{tabular}

ART Antiretroviral therapy, BMI Body mass index, HIV Human immunodeficiency virus, Hb Haemoglobin level, IQR Inter-quartile range

USD United States Dollars ( 1 USD = 2171 Tanzanian Shillings, June 2016)

a Defined as current smoking

${ }^{\mathrm{b}}$ Alcohol use defined as drinking alcohol regularly —at least three standard bottles of beer (or equivalent) per day

'Occupational risk for helminth infection defined as working in rice fields, car washing, harvesting sand, or fishing

${ }^{\mathrm{d}}$ Deworming practice in past 12 months

Table 2 Characteristics of recurrent TB cases in urban and rural Tanzania. Patients enrolled between August 2015 and February 2017 in Dar es Salaam (urban) and Ifakara (rural)

\begin{tabular}{|c|c|c|c|c|}
\hline Characteristics & All & Urban & Rural & $P$-value \\
\hline Total, $n(\%)$ & $24(100)$ & $6(25.0)$ & $18(75.0)$ & $<0.001$ \\
\hline Age in years, median (IQR) & $47(33.5-53)$ & $39(29-47)$ & $47.5(38-55)$ & 0.20 \\
\hline Male sex, $n(\%)$ & $22(91.7)$ & $6(100)$ & $16(88.9)$ & 0.55 \\
\hline HIV infection, $n(\%)$ & $5(20.8)$ & $1(16.7)$ & $4(22.2)$ & 1.0 \\
\hline Education level, $n(\%)$ & $5(0.9)$ & & & 0.55 \\
\hline No/primary school & $21(87.5)$ & $15(83.3)$ & $6(100)$ & \\
\hline Secondary/university & $3(12.5)$ & $3(16.7)$ & - & \\
\hline Occupation, n (\%) & & & & 0.002 \\
\hline Unemployed & $14(58.3)$ & - & $14(77.8)$ & \\
\hline Employed & $10(41.7)$ & $6(100)$ & $4(22.2)$ & \\
\hline Smoking ${ }^{a}, n(\%)$ & $3(12.5)$ & $2(33.3)$ & $1(5.6)$ & 0.25 \\
\hline Alcohol use ${ }^{\mathrm{b}}, n(\%)$ & $4(16.7)$ & - & $4(22.2)$ & 0.54 \\
\hline Diabetes mellitus & $1(5.3)$ & - & $1(7.7)$ & - \\
\hline People in the household, $n$ (\%) & & & & 0.99 \\
\hline$\leq 3$ & $17(70.8)$ & $4(66.7)$ & $13(72.2)$ & \\
\hline$>3$ & $7(29.2)$ & $2(33.3)$ & $5(27.8)$ & \\
\hline History of TB contact, $n(\%)$ & $7(29.2)$ & $1(16.7)$ & $6(33.3)$ & 0.63 \\
\hline Household monthly income, $n(\%)$ & & & & 0.99 \\
\hline$<100$ USD & $18(75.0)$ & $5(83.3)$ & $13(72.2)$ & \\
\hline$\geq 100$ USD & $6(25.0)$ & $1(16.7)$ & $5(27.8)$ & \\
\hline BMI in $\mathrm{kg} / \mathrm{m}^{2}$, median (IQR) & $16.9(16.3-18.4)$ & $16.5(15.7-17.0)$ & $17.1(16.5-18.8)$ & 0.14 \\
\hline Body fat in \%, median (IQR) & $10.9(7.4-14.9)$ & $7.1(5.9-8.5)$ & $11.9(10.2-15.2)$ & 0.005 \\
\hline $\mathrm{Hb}$ level in g/dl, median (IQR) & $10.8(10-12)$ & $11.2(7.2-12.9)$ & $10.5(10.1-12)$ & 0.79 \\
\hline Visiting traditional healers, $n(\%)$ & $5(20.8)$ & $1(16.7)$ & $4(22.2)$ & 0.99 \\
\hline Previous use of antibiotics, $n(\%)$ & $18(75.0)$ & $3(50.0)$ & $15(83.3)$ & 0.14 \\
\hline Any helminth infection, $n(\%)$ & $5(22.7)$ & $2(50.0)$ & $3(16.7)$ & 0.21 \\
\hline
\end{tabular}

$n$ Number, IQR Interquartile range, HIV Human immunodeficiency virus, USD United States Dollars (1 USD = 2171 Tanzanian Shillings, June 2016)

${ }^{a}$ Defined as current smoking

${ }^{\mathrm{b}}$ Alcohol use defined as drinking alcohol regularly — at least three standard bottles of beer (or equivalent) per day 
Table 3 Factors associated with recurrent tuberculosis (TB) among TB cases in urban and rural Tanzania

\begin{tabular}{|c|c|c|c|c|c|c|}
\hline \multirow{2}{*}{$\begin{array}{l}\text { Characteristics } \\
n(\%)\end{array}$} & \multicolumn{3}{|c|}{ Crude } & \multicolumn{3}{|c|}{ Adjusted } \\
\hline & $O R$ & $(95 \% C l)$ & $P$-value & $O R$ & $(95 \% C l)$ & $P$-value \\
\hline \multicolumn{7}{|l|}{ Demographics } \\
\hline Age (years) & 1.06 & $(1.04-1.09)$ & $<0.001$ & 1.06 & $(1.02-1.10)$ & 0.001 \\
\hline Male sex & 4.42 & $(1.18-16.5)$ & 0.027 & 3.04 & $(0.73-12.6)$ & 0.13 \\
\hline $\mathrm{BMI}<18.5 \mathrm{~kg} / \mathrm{m}^{2}$ & 2.47 & $(0.99-6.11)$ & 0.051 & 3.0 & $(0.85-10.3))$ & 0.087 \\
\hline Body fat (\%) & 0.98 & $(0.91-1.04)$ & 0.50 & - & - & - \\
\hline \multicolumn{7}{|l|}{ Social characteristics } \\
\hline Higher education level ${ }^{a}$ & 0.67 & $(0.2-2.29)$ & 0.52 & - & - & - \\
\hline Employed & 0.44 & $(0.2-0.99)$ & 0.046 & 1.52 & $(0.47-4.87)$ & 0.49 \\
\hline Monthly income > 200 USD & 0.76 & $(0.31-1.89)$ & 0.56 & - & - & - \\
\hline Living in the rural & 6.79 & $(2.73-16.86)$ & $<0.001$ & 3.97 & $(1.16-13.67)$ & 0.029 \\
\hline Household members $>3$ & 0.76 & $(0.32-1.8)$ & 0.53 & - & - & - \\
\hline History of TB contact & 2.5 & $(1.03-6.04)$ & 0.04 & 1.66 & $0.55-5.03$ & 0.37 \\
\hline Individual deworming ${ }^{b}$ & 0.38 & $(0.17-0.89)$ & 0.026 & 0.59 & $(0.19-1.76)$ & 0.34 \\
\hline Occupational risk ${ }^{c}$ & 1.04 & $(0.46-2.34)$ & 0.92 & - & - & - \\
\hline Smoking & 0.48 & $(0.15-1.50)$ & 0.21 & - & - & - \\
\hline Alcohol abuse & 0.70 & $(0.25-1.96)$ & 0.50 & - & - & - \\
\hline \multicolumn{7}{|l|}{ Comorbidities } \\
\hline HIV infection & 1.38 & $(0.66-2.88)$ & 0.39 & 0.51 & $(0.19-1.38)$ & 0.13 \\
\hline Diabetes mellitus & 2.93 & $(0.52-16.60)$ & 0.23 & 3.25 & $(0.43-4.65)$ & 0.25 \\
\hline Severe anaemia ${ }^{d}, g / d l$ & 1.07 & $(0.34-3.37)$ & 0.91 & - & - & - \\
\hline Haematuria & 0.3 & $(0.02-5.10)$ & 0.41 & - & - & - \\
\hline Any helminth infection & 0.99 & $(0.38-2.65)$ & 1.0 & - & - & - \\
\hline
\end{tabular}

OR Odds ratio, $\mathrm{Cl}$ Confidence interval, HIV Human immunodeficiency virus, BMI Body mass index

Logistic regression model adjusted for age, sex, BMI, employment status, setting (urban/rural), history of TB contact in the household, individual deworming, HIV infection and diabetes

${ }^{a}$ Higher education level consists of TB patients who completed their secondary of university education

${ }^{\mathrm{b}}$ Individual deworming habit in the last 12 months prior to TB diagnosis

'Occupational risk for helminth infection defined as working in rice fields, car wash, harvesting sand, or fishing

${ }^{\mathrm{d}}$ Severe anaemia defined as blood haemoglobin $(\mathrm{Hb})$ level $<8.5 \mathrm{~g} / \mathrm{dl}$

of helminth co-infections was significantly higher in the urban compared to the rural setting $(25.7 \%, 95 \% C I$ : $21.7-29.6 \%$ vs. $17.3 \%$, 95\% CI: $12.2-22.5 \% ; P=0.02$ ). The rural setting had a higher prevalence of $S$. mansoni than the urban setting and a lower prevalence of S. stercoralis. Figure 3 shows the distinctive pattern of helminth co-infections.

In a multivariate analysis, $\mathrm{TB}$ patients from the urban setting had significantly higher odds of having any helminth infection at the time of TB diagnosis compared to those from the rural setting (aOR: 2.44, 95\% CI: 1.44-4.14, $P=0.001$ ). TB patients who had taken anthelminthic medication within 12 months prior to TB diagnosis had lower odds of having acquired a helminth infection (aOR: 0.59, 95\% CI: 0.39-0.88, $P=0.009)$. Neither age, sex, HIV infection, occupational risk, nor any other cofactor was associated with helminth infection.

\section{Discussion}

Among the $668 \mathrm{~TB}$ patients from the urban and rural settings in Tanzania we studied, patients from the rural setting were older, had a lower average BMI, and lower median CD4 cell counts in case of HIV co-infection. Moreover, patients from the rural setting had more frequently recurrent TB. Whereas schistosomiasis was higher in the rural setting, the overall prevalence of helminth infections was higher in the urban setting, especially due to $S$. stercoralis.

We found differences in patient characteristics between urban and rural settings, such as age, BMI, occupation, as well as health seeking behavior (e.g., use of antibiotics prior to $\mathrm{TB}$ diagnosis and consultation of traditional healers) as reported previously from rural Tanzania [31]. The difference in time between HIV diagnosis and ART initiation in the two sites is likely explained by greater distances of rural patients to the 
Table 4 Frequency distribution of helminth infection among adult TB patients in Dar es Salaam (urban) and Ifakara (rural), Tanzania

\begin{tabular}{|c|c|c|c|c|c|c|}
\hline \multirow[t]{2}{*}{ Helminth infection } & \multirow[t]{2}{*}{ All, $n(\%)$} & \multicolumn{2}{|l|}{ Urban } & \multicolumn{2}{|l|}{ Rural } & \multirow[t]{2}{*}{$P$-value } \\
\hline & & $n(\%)$ & $95 \% \mathrm{Cl}$ & $n(\%)$ & $95 \% \mathrm{Cl}$ & \\
\hline Total & $668(100)$ & $460(68.9)$ & & $208(31.1)$ & & \\
\hline Any helminth infection ${ }^{a}$ & $154(23.1)$ & $118(25.7)$ & $21.7-29.6$ & $36(17.3)$ & $12.2-22.5$ & 0.018 \\
\hline \multicolumn{7}{|c|}{ Soil-transmitted helminths infections ${ }^{b}$} \\
\hline Strongyloides stercoralis & 89 (13.3) & $79(17.2)$ & $14.4-21.5$ & $10(4.8)$ & $1.9-7.8$ & $<0.001$ \\
\hline Hookworm & $45(6.7)$ & $26(5.7)$ & $3.7-8.1$ & $19(9.1)$ & $5.3-13.2$ & 0.12 \\
\hline Ascaris lumbricoides & $2(0.3)$ & - & - & $2(1.0)$ & - & - \\
\hline Trichuris trichiura & $5(0.8)$ & $2(0.4)$ & - & $3(1.4)$ & - & - \\
\hline \multicolumn{7}{|l|}{ Schistosomiasis } \\
\hline Schistosoma mansoni ${ }^{\mathrm{b}}$ & $15(2.3)$ & $8(1.7)$ & $0.57-3.1$ & $7(3.4)$ & 0.9 to 5.9 & 0.21 \\
\hline Schistosoma mansoni ${ }^{c}$ & $53(7.9)$ & $19(4.13)$ & $2.4-6.2$ & $34(16.4)$ & $11.4-21.6$ & $<0.001$ \\
\hline $1+$ & $19(43.2)$ & 0 & - & $19(63.3)$ & - & - \\
\hline $2+$ & $6(13.6)$ & 0 & - & $6(20.0)$ & - & - \\
\hline $3+$ & $19(43.2)$ & $14(100)$ & & $5(16.7)$ & - & - \\
\hline Schistosoma haematobium ${ }^{d}$ & $19(2.8)$ & $16(3.5)$ & $1.9-5.4$ & $3(1.4)$ & - & - \\
\hline Multiple helminth infection & & & & & & 0.63 \\
\hline None & $471(70.5)$ & $322(70.0)$ & $65.8-74.2$ & $149(71.6)$ & $65.5-77.7$ & \\
\hline Mono-infection & $159(23.8)$ & $108(23.5)$ & $19.6-27.4$ & $51(24.5)$ & 18.7-30.3 & \\
\hline Infection with $\geq 2$ species & $16(2.4)$ & $10(2.2)$ & $0.86-3.5$ & $6(2.9)$ & $0.62-5.2$ & \\
\hline
\end{tabular}

TB Tuberculosis, POC-CCA Point-of-care circulating cathodic antigen

ancluding POC-CCA positive tests (Schistosoma mansoni)

${ }^{\mathrm{b}}$ Based on stool microscopy

'Based on POC-CCA test only

${ }^{\mathrm{d}}$ Based on urine filtration

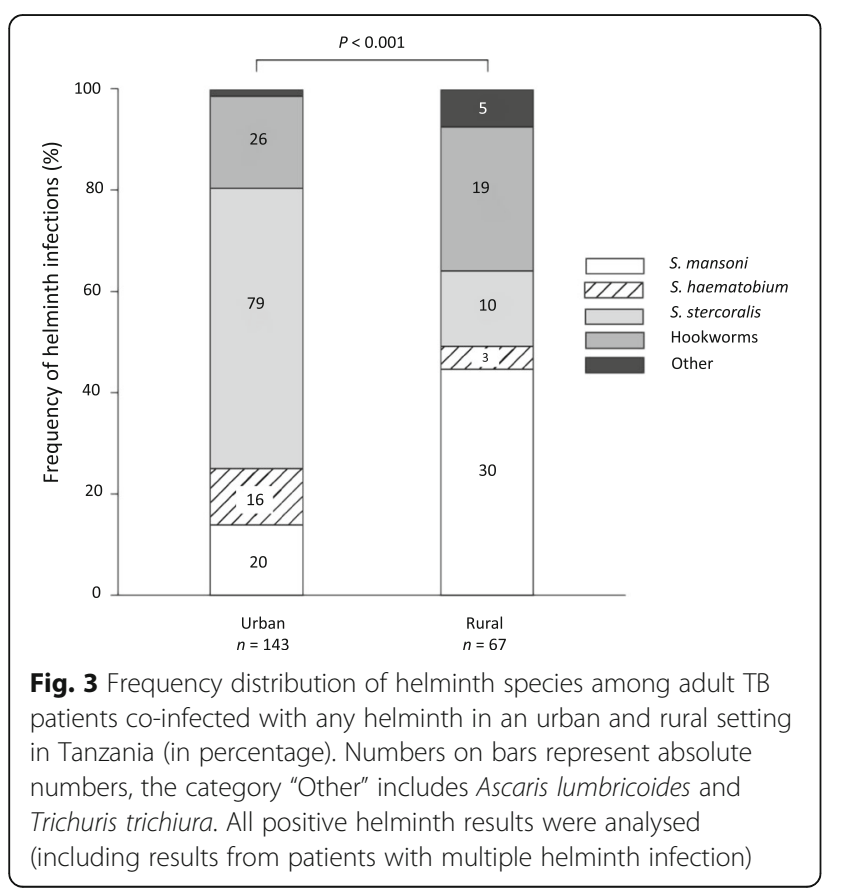

treatment center, a factor that has been shown to contribute in treatment delay [31, 32]. Rural patients comparatively had increased likelihood of visiting traditional healers due to poorer access to health facilities [33]. The resulting delay in seeking medical care has been shown to contribute to ongoing TB transmission [5, 7, 31, 34].

Helminth co-infections have been associated with rural residence $[35,36]$. In our recent work in Tanzania, we also found a positive association between $\mathrm{TB}$ and helminth co-infections in an urban setting [18]. The observed higher prevalence of helminths in the urban setting could be due to the rapid growth of the city with poor urban planning and hygiene control. This results in slum-like dwellings in large parts of the city with higher risk of infection with helminths [37]. The overall prevalence of TB and helminth co-infections we observed was comparable to previous studies elsewhere in subSaharan Africa [18, 36, 38-41]. The prevalence of S. stercoralis, the principal driver of helminthiasis in the urban setting in the current study, was comparable to that seen in previous investigations from urban Tanzania and rural Ghana $[18,42]$. The high prevalence of schistosomiasis we observed in the rural setting is likely to be settingspecific, with Ifakara Town being close to the Kilombero 
River. This was also shown in rural areas of the Democratic Republic of the Congo [43], especially among those who came in regular contact with natural open freshwater bodies (e.g., fishermen and rice famers) [44, 45]. Environmental conditions and administration of anthelminthic medication initiated on an individual basis or during mass deworming campaigns differed across our two settings, and these two factors affect prevalence and patterns of helminth co-infections. When designing public health interventions, such differences must be taken into consideration for further improvement of clinical outcomes in TB patients, as helminth coinfections alter clinical presentation and immune response to infection $[18,38,39,41]$.

The association of recurrent TB with older age and living in certain areas has also been observed elsewhere $[46,47]$, and particular comorbidities, such as HIV and diabetes mellitus, have been associated with recurrent TB $[46,48,49]$. Recurrent TB is more common in HIVpositive than HIV-negative patients [46, 50,51], and is related to poor treatment outcomes [46]. Smoking has been associated with a three-fold increased risk of developing recurrent $\mathrm{TB}$ in India [52]. However, this finding could not be confirmed in the present study. Because most recurrent cases of TB occur within 12 months of completion of treatment, follow-up after completion of treatment is important $[52,53]$.

A limitation of our study was its inability to differentiate reinfection from relapse among recurrent $\mathrm{TB}$ cases because we did not have sputum samples from prior episodes that would have made possible differentiation by molecular genotyping of $M$. tuberculosis isolates. Drug resistance information was also lacking, except for rifampicin resistance tested by Xpert MTB/ RIF assay. Although multiple techniques were used for identification of helminth co-infections, the investigation of a single stool sample in our study could have resulted in underestimation of the true prevalence of infection, especially of hookworm, T. trichiura and A. lumbricoides [54].

\section{Conclusions}

The differences in clinical and socio-demographic characteristics of TB patients in urban and rural Tanzania underline that public health interventions need to be tailored to a given setting to improve clinical outcomes of $\mathrm{TB}$ and mitigate the risk of co-infections. TB patients in the rural Tanzania are likely to be older with more recurrent TB cases, have more limited access to anthelminthic medication individually, have a longer TB diagnosis delay, and seek more frequently care from traditional healers. The overall prevalence of helminth co-infections in TB patients was higher in the urban setting, predominantly driven by $S$. stercoralis infection, but the prevalence of $S$. mansoni was higher in the rural setting. These observations may guide public health interventions that target, for example, traditional healers in the rural setting, aiming to improve early detection of TB cases and referral for anti-tuberculosis treatment. On the other hand, screening and treatment of helminths among TB patients should be improved, especially in the urban setting.

\section{Additional file}

Additional file 1: Multilingual abstracts in the five official working languages of the United Nations. (PDF $696 \mathrm{~kb}$ )

\section{Abbreviations}

aOR: Adjusted odds ratio; ART: Anti-retroviral therapy; BMl: Body mass index; BRTC: Bagamoyo Research and Training Center; CDCl: Chronic Diseases Clinic of Ifakara; CPC: Cetylpyridinium chloride; Hb: Haemoglobin; HIV: Human immune deficiency virus; IQR: Inter quartile range; LED: Light emitting diode; OR: Odds ratio; POC-CCA: Point-of-care circulating cathodic antigen;

TB: Tuberculosis; USD: United States dollar

\section{Acknowledgements}

We thank all tuberculosis patients for participating in this study. We are grateful to the St. Francis Referral Hospital and the Temeke Regional Referral Hospital, as well as the District and Regional tuberculosis coordinators from the National Tuberculosis and Leprosy Programme. We are indebted to the local study staff at both sites for their diligent work.

\section{Funding}

This work was supported by funding from the Rudolf Geigy Foundation (Basel, Switzerland).

\section{Availability of data and materials}

The datasets that were used for analysis and preparation of this manuscript are not publicly available due the national policy on data sharing. The datasets will be available from the corresponding author upon reasonable request where concerned parties will sign a data transfer agreement approved by the Medical Research Coordinating Committee.

\section{Author's contribution}

Conceived and designed the study: GS, JH, EL, FM, LR, MS, KS, SG, KR, MT, MW and LF. JH, GS, YM, GM, MW and LF analysed the data. GS, JH, FM, KS, FB and RN contributed clinical data. MS, LK, FB, SK and LR contributed laboratory data. JH and GS prepared the first draft of the manuscript. LR, GM, $\mathrm{CH}, J U, \mathrm{MT}, \mathrm{MW}$ and LF contributed in the first major revision of the manuscript. All authors contributed in final manuscript revisions and approved the final version.

\section{Ethics approval and consent to participate}

The study was approved by the institutional review board of the Ifakara Health Institute (IHI; reference no. IHI/IRB/04-2015), the Medical Research Coordinating Committee of the National Institute of Medical Research in Tanzania (NIMR; reference no. NIMR/HQ/R.8c/Nol. 1/357), and the Ethics Committee of the Northwestern and Central Switzerland (EKNZ; reference no. UBE-15/42). All patients gave written informed consent before enrolment into the study.

\section{Consent for publication}

Not applicable.

\section{Competing interests}

The authors declare that they have no competing interests.

\section{Author details}

${ }^{1}$ Ifakara Health Institute, Dar es Salaam, Tanzania. ${ }^{2}$ Swiss Tropical and Public Health Institute, Basel, Switzerland. ${ }^{3}$ University of Basel, Basel, Switzerland. 
${ }^{4}$ Institute of Social and Preventive Medicine, University of Bern, Bern, Switzerland.

\section{Received: 1 September 2017 Accepted: 12 March 2018 Published online: 24 March 2018}

\section{References}

1. WHO. Global Tuberculosis Report, vol. 2016. Geneva: World Health Organization; 2016.

2. Ministry of Health and Social Welfare. First tuberculosis prevalence survey in the United Republic of Tanzania. In: Dar es Salaam; 2013.

3. WHO. Global Tuberculosis Report, vol. 2015. Geneva: World Health Organization; 2015

4. Senkoro M, Hinderaker SG, Mfinanga SG, Range N, Kamara DV, Egwaga S, et al. Health care-seeking behaviour among people with cough in Tanzania: findings from a tuberculosis prevalence survey. Int J Tuberc Lung Dis. 2015; 19(6):640.

5. Ngadaya ES, Mfinanga GS, Wandwalo ER, Morkve O. Delay in tuberculosis case detection in Pwani region, Tanzania. A cross sectional study. BMC Health Serv Res. 2009;9:196. https://doi.org/10.1186/1472-6963-9-196.

6. Storla DG, Yimer S, Bjune GA. A systematic review of delay in the diagnosis and treatment of tuberculosis. BMC Public Health. 2008;8 https://doi.org/10. 1186/1471-2458-8-15.

7. Sreeramareddy CT, Panduru KV, Menten J, Van den Ende J. Time delays in diagnosis of pulmonary tuberculosis: a systematic review of literature. BMC Infect Dis. 2009:9 https://doi.org/10.1186/1471-2334-9-91.

8. WHO. Diagnostic and treatment delay in tuberculosis. Geneva: World Health Organization; 2006

9. Golub JE, Bur S, Cronin WA, Gange S, Baruch N, Comstock GW, et al. Delayed tuberculosis diagnosis and tuberculosis transmission. Int J Tuberc Lung Dis. 2006;10:24-30.

10. Uplekar M, Weil D, Lonnroth K, Jaramillo E, Lienhardt C, Dias HM, et al. WHO's new end TB strategy. Lancet. 2015;385:1799-801. https://doi.org/10. 1016/S0140-6736(15)60570-0

11. WHO. The end TB strategy. Geneva: World Health Organization; 2015.

12. Deribew A, Abebe G, Apers L, Jira C, Tesfaye M, Shifa J, et al. Prejudice and misconceptions about tuberculosis and HIV in rural and urban communities in Ethiopia: a challenge for the TB/HIV control program. BMC Public Health. 2010;10 https://doi.org/10.1186/1471-2458-10-400.

13. van der Hoeven $M$, Kruger $A$, Greeff $M$. Differences in health care seeking behaviour between rural and urban communities in South Africa. Int J Equity Health. 2012;11

14. Shen X, Xia Z, Li X, Wu J, Wang L, Li J, et al. Tuberculosis in an urban area in China: differences between urban migrants and local residents. PLoS One. 2012;7

15. Faurholt-Jepsen D, Range N, Praygod G, Jeremiah K, Faurholt-Jepsen M, Aabye MG, et al. Diabetes is a strong predictor of mortality during tuberculosis treatment: a prospective cohort study among tuberculosis patients from Mwanza, Tanzania. Tropical Med Int Health. 2013;18:822-9. https://doi.org/10.1111/tmi.12120.

16. Isanaka S, Mugusi F, Urassa W, Willett WC, Bosch RJ, Villamor E, et al. Iron deficiency and anemia predict mortality in patients with tuberculosis. J Nutr. 2012;142:350-7.

17. Isanaka S, Aboud S, Mugusi F, Bosch RJ, Willett WC, Spiegelman D, et al. Iron status predicts treatment failure and mortality in tuberculosis patients: a prospective cohort study from Dar es salaam, Tanzania. PLoS One. 2012;7

18. Mhimbira FA, Hella J, Kamwela L, Sasamalo M, Chiryamkubi M, Maroa T, et al. Prevalence and clinical relevance of helminth and tuberculosis coinfections in urban Dar es salaam, Tanzania. PLoS Negl Trop Dis. 2017;11

19. National Bureau of Statistics. Population and housing census. Dar es Salaam. 2012:2013.

20. Steiner A, Hella J, Gruninger S, Mhalu G, Mhimbira F, Cercamondi Cl, et al. Managing research and surveillance projects in real-time with a novel opensource eManagement tool designed for under-resourced countries. J Am Med Inf Assoc. 2016:23:916-23.

21. Mhalu G, Hella J, Doulla B, Mhimbira F, Mtutu H, Hiza H, et al. Do instructional videos on sputum submission result in increased tuberculosis case detection? A randomized controlled trial. PLoS One. 2015;10:e0138413. https://doi.org/10.1371/journal.pone.0138413.

22. Said K, Hella J, Mhalu G, Chiryankubi M, Masika E, Maroa T, et al. Diagnostic delay and associated factors among patients with pulmonary tuberculosis in Dar es salaam, Tanzania. Infect Dis Poverty. 2017;6
23. Letang E, Kalinjuma AV, Glass TR, Gamell A, Mapesi H, Sikalengo G, et al. Cohort profile : the Kilombero and Ulanga antiretroviral cohort (KIULARCO). Swiss Med Wkly. 2017;147:1-9.

24. National Tubercuosis and Leprosy Programe. Manual for the Management of Tuberculosis and Leprosy. Dar es Salaam; 2013.

25. Lumb R, Van Deun A, Bastian I, Fitz-Gerald M. Laboratory diagnosis of tuberculosis by sputum microscopy. SA Pathology; 2013.

26. Hiza H, Doulla B, Sasamalo M, Hella J, Kamwela L, Mhimbira F, et al. Preservation of sputum samples with cetylpyridinium chloride (CPC) for tuberculosis cultures and Xpert MTB/RIF in a low-income country. BMC Infect Dis. 2017:17:1-6.

27. Leuenberger A, Nassoro T, Said K, Fenner L, Sikalengo G, Letang E, et al. Assessing stool quantities generated by three specific Kato-Katz thick smear templates employed in different settings. Infect Dis Poverty. 2016;5:58.

28. WHO. Definitions and reporting framework for tuberculosis-2013 revision. Geneva: World Health Organization; 2013.

29. Lamberton PHL, Kabatereine NB, Oguttu DW, Fenwick A, Webster JP. Sensitivity and specificity of multiple Kato-Katz thick smears and a circulating cathodic antigen test for Schistosoma mansoni diagnosis preand post-repeated-praziquantel treatment. PLoS Negl Trop Dis. 2014;8

30. American Diabetes Association. Diagnosis and classification of diabetes mellitus. Diabetes Care. 2004;27(Supplement 1):S5-10.

31. Verhagen $L$, Kapinga $R$, van Rosmalen-Nooijens KAW. Factors underlying diagnostic delay in tuberculosis patients in a rural area in Tanzania : a qualitative approach. Infection. 2010:433-46.

32. Mfinanga SG, Mutayoba BK, Kahwa A, Kimaro G, Mtandu R, Ngadaya E, et al. The magnitude and factors associated with delays in management of smear positive tuberculosis in Dar es salaam, Tanzania. BMC Health Serv Res. 2008; 8 https://doi.org/10.1186/1472-6963-8-158.

33. Sandler G. South Africa: Self-medication. Lancet. 1990:335

34. Wandwalo ER, Mørkve O. Delay in tuberculosis case-finding and treatment in Mwanza, Tanzania. Int J Tuberc Lung Dis. 2000:4:133-8.

35. Walson JL, Stewart BT, Sangaré L, Mbogo LW, Otieno PA, Piper BKS, et al. Prevalence and correlates of helminth co-infection in kenyan HIV-1 infected adults. PLoS Negl Trop Dis. 2010;4

36. Alemu G, Mama M. Intestinal helminth co-infection and associated factors among tuberculosis patients in Arba Minch, Ethiopia. BMC Infect Dis. 2017;17

37. UN-HABITAT. Informal settlements and finance in Dar es salaam. In: Tanzania; 2010

38. Rafi W, Ribeiro-rodrigues R, Ellner JJ, Salgame P. Coinfection-helminthes and tuberculosis. Curr Opin HIV AIDS. 2012;7:239-44.

39. Salgame P, Yap GS, Gause WC. Effect of helminth-induced immunity on infections with microbial pathogens. Nat Immunol. 2013;14:1118-26.

40. Babu S, Nutman TB. Helminth-tuberculosis co-infection: an immunologic perspective. Trends Immunol. 2016;37:597-607.

41. Dinardo AR, MacE EM, Lesteberg K, Cirillo JD, Mandalakas AM, Graviss EA, et al. Schistosome soluble egg antigen decreases Mycobacterium tuberculosisspecific CD4+ T-cell effector function with concomitant arrest of macrophage phago-lysosome maturation. J Infect Dis. 2016;214:479-88.

42. Yelifari $L$, Bloch $P$, Magnussen $P$, van Lieshout L, Dery $G$, Anemana $S$, et al. Distribution of human Oesophagostomum bifurcum, hookworm and Strongyloides stercoralis infections in northern Ghana. Trans R Soc Trop Med Hyg. 2005;99:32-8

43. Madinga J, Linsuke S, Mpabanzi L, Meurs L, Kanobana K, Speybroeck N, et al. Schistosomiasis in the Democratic Republic of Congo: a literature review. Parasit Vectors. 2015;8

44. Tukahebwa EM, Magnussen P, Madsen H, Kabatereine NB, Nuwaha F, Wilson $S$, et al. A very high infection intensity of Schistosoma mansoni in a Ugandan Lake Victoria fishing community is required for association with highly prevalent organ related morbidity. PLoS Negl Trop Dis. 2013;7

45. Mazigo HD, Nuwaha F, Kinung'hi SM, Morona D, Pinot de Moira A, Wilson S, et al. Epidemiology and control of human schistosomiasis in Tanzania. Parasit Vectors. 2012:5:274

46. Gadoev J, Asadov D, Harries AD, Parpieva N, Tayler-Smith K, Isaakidis $P$, et al. Recurrent tuberculosis and associated factors: a five - year countrywide study in Uzbekistan. PLoS One. 2017;12

47. Hung CL, Chien JY, Ou CY. Associated factors for tuberculosis recurrence in Taiwan: a nationwide nested case-control study from 1998 to 2010. PLoS One 2015:10:1-11

48. Wurie FB, Lawn SD, Booth H, Sonnenberg P, Hayward AC. Bioaerosol production by patients with tuberculosis during normal tidal breathing: implications for transmission risk. Thorax. 2016:549-54. 
49. Sanghani RN, Udwadia ZF. Association of diabetes and tuberculosis: impact on treatment and post-treatment outcomes. Thorax. 2013;68:202-3.

50. Jasmer RM, Bozeman L, Schwartzman K, Cave MD, Saukkonen JJ, Metchock B, et al. Recurrent tuberculosis in the United States and Canada: relapse or reinfection? Am J Respir Crit Care Med. 2004;170:1360-6.

51. Sonnenberg P, Murray J, Glynn JR, Shearer S, Kambashi B, Godfrey-Faussett P. HIV-1 and recurrence, relapse, and reinfection of tuberculosis after cure: a cohort study in south African mineworkers. Lancet. 2001;358:1687-93.

52. Thomas A, Gopi P, Santha T, Chandrasekaran V, Subramani R, Selvakumar N, et al. Predictors of relapse among pulmonary tuberculosis patients treated in a DOTS programme in South India. Int J Tuberc Lung Dis. 2005;9:556-61.

53. Guerra-Assuncao JA, Houben RMGJ, Crampin AC, Mzembe T, Mallard K, Coll $F$, et al. Recurrence due to relapse or reinfection with Mycobacterium tuberculosis: a whole-genome sequencing approach in a large, populationbased cohort with a high HIV infection prevalence and active follow-up. J Infect Dis. 2015;211:1154-63.

54. Knopp S, Mgeni AF, Khamis IS, Steinmann P, Stothard JR, Rollinson D, et al. Diagnosis of soil-transmitted helminths in the era of preventive chemotherapy: effect of multiple stool sampling and use of different diagnostic techniques. PLoS Negl Trop Dis. 2008;2

\section{Submit your next manuscript to BioMed Central} and we will help you at every step:

- We accept pre-submission inquiries

- Our selector tool helps you to find the most relevant journal

- We provide round the clock customer support

- Convenient online submission

- Thorough peer review

- Inclusion in PubMed and all major indexing services

- Maximum visibility for your research

Submit your manuscript at www.biomedcentral.com/submit 